\title{
Editorial
}

\section{Cambiar para mejorar: ¿qué y cómo?}

El eslogan ha pegado; todos coincidimos en que "hay que cambiar para mejorar", pero queda como un interrogante a quienes hay que mejorar y por lo tanto qué es lo que se va a cambiar y cómo se va a cambiar. El tema del "modelo económico" salta a la arena del debate nacional. En los meses preelectorales y postelectorales tanto los partidos contendientes como diversas instituciones o centros de investigación han coincidido en listar, quizás no siempre en el mismo orden, un rosario de problemas económicos lo suficientemente largo para comprender que estamos en una crisis económica, social y política de difícil salida. Y esta salida se convierte en más conflictiva porque difieren la interpretación de los problemas, las políticas propuestas y-en consecuencia lo que llamamos el "modelo económico" o mecanismo de estructuración económica que ya en el corto plazo indique qué es lo que quiere lograr en el más largo plazo.

Llama la atención que siendo la mayoria de diagnósticos "análisis de izquierda" (amplia situación de pobreza-indigencia, disparidad de ingresos, creciente desempleo y tasa de inflación, insatisfacción generalizada de las necesidades básicas...), las soluciones recomendadas sean "politicas y modelos de derecha: "hacia una economía de mercado", de libre empresa, de liberalización de los precios, de privatización, de vuelta al "individuo" más que a la persona social. Llama la atención que, siendo los problemas del desequilibrio interno los que más afligen a la mayoría desamparada de la población, se haga girar la atención y se enfaticen los problemas del desequilibrio externo, el que nuestra economia sostiene frente al mercado internacional comercial y financiero. En otras palabras, teniendo al interior del país una gran "deuda interna" en la generación de empleo, ingresos, mejora del nivel socio-econó- 
mico..., parezca más importante, incluso requisito previo, la compostura de la "deuda externa", presuponiendo que, con otro tiempo de espera, se dará solución a los problemas del desarrollo interno, y que la misma guerra (un ente advenedizo del exterior) puede dificultar, pero no anular los efectos de las políticas económicas.

La razón principal de las discrepancias en los diagnósticos, en las políticas $y$ en el modelo propuestos se halla en la diferente lectura histórica sobre el origen y la cronologia causal de lo que llamamos "nuestros problemas económicos estructurales". Se ha convertido en interpretación y teoria ponderada que el origen temporal de nuestra gran crisis se sitúa a partir de los años 1980, y su origen causal en la creciente y desventurada intervención estatal en el quehacer económico nacional. Con esta interpretación las décadas anteriores a la presente ya no son "lo que el viento se llevó", sino el parámetro que oriente a reconstruir el modelo económico más acertado. Pero to acertado de un modelo dependerá de lo acertada que sea la lectura real de nuestra historia.

Echando marcha atrás veamos cuáles eran los rasgos económicos generales que tipificaron la década anterior, 1970-1979. Aunque esa década se abre con todo un proceso internacional de estanflación que nos afecta sensiblemente $y$ arranca luego de una triste guerra de 100 horas con el pais vecino, sin embargo la economía presenta un conjunto de rasgos benévolos, que hoy se platean como el punto de partida o el trampolín para dar el salto hacia el desarrollo interno del país.

- En esa década la economía presentó una tasa de crecimiento real promedio de un $5 \%$, superior a la tasa de crecimiento poblacional.

- La Balanza de Pagos presenta un relativo equilibrio externo, contablemente, donde unas partidas compensan los déficits anuales de las otras, sin que haya una presión por la "devaluación monetaria"; la deuda externa crece, tanto la pública como la privada, pero es una deuda tolerable y pagable con un reducido porcentaje de exportaciones.

- Tampoco el "presupuesto estatal" plantea un gravoso déficit estatal, aunque su estructura de ingresos y el destino global de los gastos no sean propiamente muy sociales. Pero contablemente hay un relativo equilibrio.

- El regulador de la economía es la "economía de mercado" y libre empresa, muy poco impresionada por las orientaciones apuntadas en los Planes de Desarrollo Económico y Social. Incluso los Gobiernos de esas décadas fungen como "Estados-Benefactores" del sector productivo 
tanto por la amplia y costosa infraestructura de que le dota como por la propicia legislación comercial y fiscal con que protege y financia a dicho sector.

- Se da una privatización de aquellas instituciones que hoy se reclama deben ser reprivatizadas.

En resumen, se dan las condiciones o prerrequisitos, internos y externos, que hoy se afirma son la precondición para el desarrollo económico o servicio de la "deuda interna" a favor de las mayorias laborales. Sin embargo, puestas todas estas condiciones fundamentales, aparecen meridianamente los verdaderos problemas de nuestra economia. Son ellos la elevada "concentración económica del capital y de la renta en relativamente pocas manos", a lo que se irá añadiendo la "concentración geográfica" urbana frente a la desolación rural. El derivado o el negativo del modelo de mercado será la situación de "pobreza generalizada" que alcanza a dos tercios de la población laboral, situándose un cincuenta por ciento en estado de "extrema pobreza" de acuerdo a estadísticas nacionales y externas. Ni la economia de mercado, ni las precondiciones de equilibrios internos o externos, habian logrado poner límite a los dos principales problemas estructurales: concentración económica y probreza generalizada. Más aún, la libre empresa o sector productivo influyente impondrán la mayor resistencia a los intentos de transformación social, taponando con ello cualquier salida legal o parlamentaria favorable a estos cambios sociales. El recurso a la fuerza bruta y el recurso al "explosivo", como última razón, fueron inventos de las "derechas" en esa década. Por ello cabe la pregunta: ¿quién inició la guerra y por qué se inició la guerra?.

Seguir sosteniendo que la guerra es una "importación no tradicional", emanación de los conflictos ideológicos y armados de las dos superpotencias es pecar a la vez de realismo y de idealismo. Si a nuestro conflicto lo llamamos "guerra civil" es porque nació dentro y desde dentro. Asi lo vieron también aquel grupo de militares, que entienden de guerra, y que dieron un "golpe al Estado" por proteger y garantizar una situación injusta en sus vertientes sociales, económicas y politicas. EI realismo y el idealismo nacional nos fuerzan a leer nuestra secuencia histórica de "concentración-pobreza-guerra y más pobreza con más guerra". Si buscamos argumentos en el "orden internacional" debemos entender que nuestra guerra es una de ese largo y amplio serial de 160 guerras que se vienen librando desde 1950 en nuestro planeta; se trata de "guerras sistemáticas", por cuanto buscan en cada lugar una reestructuración del sistema o del modelo incapaz de dar respuestas a las mayoritarias demandas sociales.

La crisis no comenzó en 1980 , pero sí continuó y se ha profundizado 
en la presente década. No basta decir que somos una "economía EN guerra", como si la economía y la guerra caminaran por dos calles diferentes. Somos una "economía DE guerra, aunque el armamento no lo hagamos en casa. La guerra es el REGULADOR y el condicionante no sólo de las grandes variables macroeconómicas, sino de los principales sectores económicos nacionales: la producción y la productividad del sector privado, el presupuesto estatal (presupuesto de guerra y de deuda externa), de cada una de las partidas de la balanza de pagos, de nuestra deuda externa y también de la condicionada y condicionante ayuda externa. Parecería que esta tesis encuentra fuertes resistencias y se la interpreta como "posición derrotista", como si fuera imposible reactivar la economia mientras no se le encuentre solución al coflicto armado. Este idealismo, propio de quienes "no hacen la guerra", sólo admite una respuesta: "el tiempo lo dirá"...

Hay un hecho difícil de negar y es que la guerra, los efectos derivados de la guerra y la deficiente administración pública han venido a deteriorar y discriminar aun más la penosa situación de las mayorías laborales. La misma guerra ha sido discriminante por cuanto se ha librado o desarrollado sobremanera en las zonas tradicionalmente discriminadas y más pobres del pais, y junto al sistema forzado de reclutamiento militar ha venido a afectar más penosamente, en lo económico y en lo psicológico, a sectores más necesilados del país. El servicio creciente de la deuda externa, en buena parte dueda de guerra, se ha convertido en título colorado para dejar de atender a los reclamos de la "deuda interna", el empleo, los ingresos y la satisfacción de las necesidades familiares de un amplio sector popular. En forma semejante, el presupuesto estatal, que ha llegado a dedicar hasta un $45 \%$ del gasto global a las partidas de defensa-seguridad y servicio de la deuda, se viene mostrando incapaz de atender a las partidas sociales de salud, educación, bienestar.. y otras partidas que hubieran posibilitado mayor inversión y creación de empleos-ingresos. Las medidas tributarias, en buena parte exigencias del proceso de guerra, logran transferir, por un efecto en cascada, sus ondas crecientes hacia los precios finales. Alternativa o secuencialmente el binomio inflación-devaluación, la primera vigente desde hace quince afios, han ido deteriorando el ya contraido poder de compra real del colón interno, a lo largo de una "guerra civil monetaria" con sus vencedores y sus vencidos con el arma de los precios. El llamado sector productivo no ha sido protagonista ausente de esta batalla y la corrupción no es propiedad privada de la administraicón pública; también parece ser propiedad pública de la administración privada.

Al leer en forma diferente el pasado y el presente es normal que proyectemos un diferente modelo económico para el futuro. Se diría más bien que nos movemos arrastrados por una "Ley del Péndulo", que nos 
lleva de un extremo al otro. En las décadas pasadas privó y primó el sector privado y la economía de mercado; el resultado social no fué positivo, aunque algunos prefieren silenciar el pasado. En la presente década se intentó más bien una "politización partidista" que una estatización social que en las adversas circunstancias internas y externas (amén de la deficiente gestión ) tampoco dió resultado. A estas fechas que el "reloj de Arena" da la vuelta y vuelve a sonar la hora de la economia de mercado y de la libre empresa. En verdad ésto es caminar hacia atrás y no hacia el futuro.

En esta década, en que tanto se ha hablado de invasión e intervencionismo estatal, la Administración Pública, y no por falta de técnicos ni de técnicas, ha cortado con una tradición y con una función primordial de todo Gobierno: la preparación de Planes de Desarrollo Económico y Social. También en este aspecto se ha aventurado la economía en otra ley del péndulo: programa de reactivación, 1980-1982; programa de estabilización, 1982-1984, con congelamiento únicamente de los salarios; programa de reactivación de 1986 a nuestros días. Los hechos internos y las presiones externas han sido más fuertes que las intenciones de dichos programas. Adicionalmente y más o menos conscientes de su esperada inoperancia, los programas anuales económicos y monetarios eran objeto de "secreto oficial". Se diria que era una economia que viajaba sin radar; y con ello, quienes predican la no intervención estatal en la gerencia económica, encontraban un argumento, algo extraño, de que el Estado no orientaba la economía. Lo más cierto y realista es admitir que a lo largo de la presente década se ha ido ampliando una brecha - y una teoria - entre un sector privado que perdia poder y una administración partidista que no logró gerenciarlo socialmente.

Como resultado, al terminar la década, se aprecian dos fallas fundamentales para mostar el modelo económico del ya presente-futuro. No hay de hecho un Plan de Desarrollo Económico y Social, que arrancando de un diagnóstico realista marque objetivos de largo plazo, retrotraídos a objetivos y políticas de mediano y corto plazo, que den traducción eficiente al idealismo de ir corrigiendo el estado de suma pobreza-indigencia. Simultáneamente, queda el gran confusionismo de los papeles y funciones que competen a la Administración Pública y al Sector Privado. Aunque de momento ambos lleven los mismos colores del partido, sin embargo se presagia una menor orientación del Sector Público y una mayor planificación de la economía por el mercado. No fué asi la forma con que las economias capitalistas - sin mencionar las socialistas- enfrentaron su problema de reconstrucción y de desarrollo en las décadas siguientes a los años 1950 .. Procuraron organizar su modelo a modo de "economias concertadas", de planificación indicativa. $Y$ dato adicional que nos puede ayudar, en ese diálogo entre sectores públicos y privados las "matrices 
intersectoriales" servian como orden de agenda para dicha acción concertada.

En el país carecemos, de momento, de un Plan de Desarrollo Económico y Social; no tenemos marcadas las etapas y las polítcas del más corto y del más largo plazo. Sin un plan ordenado se corre el riesgo de dajar en simple idealismo el anunciado proyecto de erradicar o aminorar en el próximo quinquenio la generalizada probreza-indigencia. Tampoco es solución la referencia a una "Economia Social de Mercado". Dada nuestra estructuración productiva, nuestro mercado no puede ser social. Las líneas que hoy se enfatizan son la privatización, la libertad, la iniciativa individual...; pero el primer problema redical es la "justicia social". Aplicado a nuestras circunstancias vale el dicho: "la libertad oprime y la ley libera". Sin reestructuración del mercado, o dicho al revés, con una estructura de concentración económica, no florecerá lo "social". También ésta es una tesis básica de la "Economia Social de Mercado".

En cuanto siva a orientar un modelo económico social, recordemos que se dispone de una "Matriz Insumo-Producto, 1978" (BCR). Diez años no vuelve obsoleta esta matriz-1978, por cuanto ella describe las interrelaciones estructurales de los sectores productivos. En varias ocasiones y artículos se ha comentado que los sectores económicos que responden o pudieran responder a la satisfacción de las necesidades básicas, (canasta familiar) son - de acuerdo a la matriz- sectores claves para la reactivación interna de la economía, tanto por su elevada demanda de insumos como por su oferta de productos al conjunto de las ramas transformadoras y al mercado final. La respuesta social y la mayor capacidad de reactivación económica pudieran avanzar al unisono. El mercado "pudiera", pero hace falta un Plan de reestructuración y un Plan que fije las "sendas del desarrollo".

A falta de un Plan hay una realidad que se impone: "la opción preferencial por los pobres". Se ha dicho que ellos serán los "privilegiados". Económicamente ésto tiene una secuencia de respuestas. Pobreza-indigencia significa insatisfacción de un conjunto de necesidades básicas; la canasta familiar ampliada. Hay un conjunto de sectores económicos que pueden o pudieran responder a la satisfacción de estas necesidades básicas. Estos sectores tienen como caracteristica general su mayor capacidad de reactivación interna de la economía, al mismo tiempo que responderian a esta demanda social. El problema es que también en estos sectores se aprecia una notable concentración económica. El modelo que aceptara centrar su eje primordialmente en la satisfacción de las necesidades básicas iria dando una respuesta al problema del desequilibrio o "dueda interna" de nuestra economia. Pero el modelo no puede olvidar el problema del "desequilibrio extemo"; no hay autarquia posible, sino elevada dependencia externa. Por ello hay que priorizar las 
importaciones, las que realmente son "claves" al modelo; las requeridas por los propios sectores claves, servidores de otros tantos sectores. Hay que relegar, por un largo momento, las menos necesarias y suntuarias. Si se liberalizan las importaciones, no se cumplirá con este requisito básico para la reactivación económica, y más bien volverá a jugar el "efecto-demostración" y las "zonas-rosas económicas". El modelo debe apoyar técnica y comercialmente las exportaciones tradicionales y no tradicionales realistas, requeridas por el eje interno de la economia; pero sin comprometer con ello la producción de granos y alimentos básicos, por ser el soporte de la dieta básica, poseer una elevada capacidad de reactivación interna, junto con una vocación para desarrollar la agroindustria alimentaria. Esta partida económica no puede quedar a la merced de renovadas importaciones o de una ayuda externa alimentaria. El modelo no puede prescindir de una fuerte ayuda externa diversificada. También en ésto seguiremos siendo dependientes, pero buscando nuevas alternativas.

Pero ni éste, ni ningún otro modelo, puede funcionar con la guerra; esto no es "derrolismo" sino realismo. Porque la pobreza y la guerra son causa y efecto en nuestra economia. Si no cambiamos a las dos, no mejoraremos en nada. 